\title{
Review on the Interactions of Green Computing and Computational Intelligence techniques and their Applications to Real-World Problems
}

\author{
Oscar Castillo, Patricia Melin \\ Division of Graduate Studies, Tijuana Institute of Technology, Tijuana 22379, Mexico. \\ Correspondence to: Prof./Dr. Oscar Castillo, Division of Graduate Studies, Tijuana Institute of Technology, Calzada Tecnologico \\ s/n, Tijuana 22379, Mexico. E-mail: ocastillo@tectijuana.mx \\ How to cite this article: Castillo O, Melin P. Review on the Interactions of Green Computing and Computational Intelligence \\ techniques and their Applications to Real-World Problems. J Smart Environ Green Comput 2021;1:103-19. \\ https://dx.doi.org/10.20517/jsegc.2021.01
}

Received: 4 Jan 2021 First Decision: 1 May 2021 Revised: 8 Mar 2021 Accepted: 15 Jun 2021 First online: 15 Jun 2021

Academic Editor: Giancarlo Succi Copy Editor: Yue-Yue Zhang Production Editor: Yue-Yue Zhang

\begin{abstract}
The present paper describes a comprehensive review on the current state of art on the interactions of the green computing and computational intelligence areas and their applications to real world-problems. Green computing can be viewed as the responsible use of computers and their corresponding resources for achieving environmental and ecological goals. On the other hand, computational intelligence is an area consisting of methods and models for building intelligent systems, such as neural network models, fuzzy logic systems and genetic algorithms. The interaction of the two areas could produce intelligent systems that can achieve environmentally responsible and eco-friendly applications, which can help really achieve the main goals of green computing. The present review summarizes the most relevant existing works on these areas, as well as the current applications that have been done to the moment. In addition, an analysis on the trends of current existing works and a discussion of possible research trends are also offered. The significance of this paper is the presentation in a unified way of the main concepts of green computing and computational intelligence, as well their current and future applications. We strongly believe that this paper could help lay the foundation for a new hybrid area combining green computing with computational intelligence, which would be very important because up to now both areas have been flourishing apart and they could both benefit by interacting with each other.
\end{abstract}


Keywords: Green computing, computational intelligence, hybrid systems, intelligent systems

\section{INTRODUCTION}

Nowadays, green computing has been receiving increasing attention from industry, government and academia. Green computing can be thought of as the responsible use of computers and their corresponding resources for achieving environmental and ecological goals. More generally, it is also defined as the study of designing, manufacturing/engineering, utilizing and discarding of computing devices in a way that decreases the impact on the environment for the benefit of society. For this reason, it is of upmost importance to consider this area in every aspect of human life. At the same time, the use of computational intelligent techniques has also become very important for everyday life, ranging from domestic appliances to autonomous systems and automated medical diagnosis. In this form, we come to realize that the interaction of both green computing and soft computing should become very important in the near future $e^{[1-6]}$.

Computational intelligence is a relatively new branch of computer science that deals with the development of intelligent systems based on relatively new intelligent models, e.g., fuzzy systems, neural networks, genetic algorithms, swarm intelligence and others ${ }^{[7-9]}$. Fuzzy logic was originally proposed by Zadeh and generalizes traditional Boolean logic by allowing truth values to be between 0 and 1 . The main goal of fuzzy logic is to represent and handle the intrinsic uncertainty in real-world problems by using fuzzy systems. Neural networks are models that simulate the human brain by representing neural networks with mathematical models (as artificial networks) and by using an iterative learning algorithm. Neural networks can learn from real-world data to form supervised or unsupervised neural systems that can be applied in many real-world situations ranging from classification and pattern recognition to time series prediction. Genetic algorithms are computer methods that simulate natural evolution and the principle of survival of the fittest for achieving an efficient search for solutions to optimization problems. Genetic algorithms and related evolutionary techniques have also found many applications, such as in scheduling, planning, manufacturing and others. Swarm intelligence consists of techniques based on collective intelligence, such as particle swarm intelligence, ant colony optimization, the grey wolf optimizer, firefly algorithm, flower pollination, bee colony optimization and others. These recent techniques have been applied in general optimization problems, as well as in optimization of fuzzy and neural models. In addition, the prudent combination of several of the previous techniques can be utilized for building powerful hybrid intelligent systems, which can solve many real-world problems in different areas of applications, such as intelligent control, robotics, pattern recognition, diagnosis, classification and others ${ }^{[10-12]}$.

Green computing, which is also sometimes called green technology, can be thought of as the responsible use of computers and their corresponding resources for achieving environmental and ecological goals. The usual practices in this area include the following activities: implementation of energy-efficient central processing units, servers and peripherals, as well as plans for reducing resource consumption and for the proper disposal of electronic waste ${ }^{[13,14]}$.

One of the first initiatives that was put toward in green computing in the United States was the voluntary labeling program known as Energy Star. This program was initially put forward by the Environmental Protection Agency in 1992 for promoting efficient use of energy in hardware of all types in the United States. Since that time, the Energy Star label has become a common thing in the United States, especially in notebook computers and displays. After this, similar programs have been proposed in Europe, Asia and worldwide with the same goals. 
In Figure 1, we illustrate and summarize the main ideas of green computing.

The contribution of this paper is the proposed review of the existing works in the literature, where both green computing and computational intelligence have been used together in real-world problems, so that the potential advantages of the combination of these computer science areas can be evaluated and possible future works can be envisioned. In addition, based on the analysis of the existing works, another contribution of the paper is the proposal of future trends (in the short, medium and long terms) for possible research works based on the combination of green computing and computational intelligence.

The rest of the paper is organized as follows. Section 2 offers an overview of existing works in the literature on intelligent systems applied to green computing problems. Section 3 presents a scientometric analysis of green computing and computational intelligence techniques. Section 4 outlines possible future trends of research on the intersection of computational intelligence and green computing. Finally, Section 5 summarizes the conclusions and outlines interesting lines of research.

\section{OVERVIEW OF EXISTING WORKS ON INTELLIGENT SYSTEMS APPLIED TO GREEN COMPUTING}

In this section, an overview of the most relevant existing works in the literature where intelligent systems have been applied to green computing is presented. We found 255 papers using Scopus of Elsevier where both areas are mentioned. A brief description of a sample of the most relevant works is presented in this section, so that the relevance and impact of both green computing and computational intelligence can be better appreciated. We selected 18 papers as a sample of the most representative and recent works, to be discussed in more detail in the remaining paragraphs of this section. In the following section, we offer a scientometric analysis of the total set of 255 papers, but here we only briefly describe a sample of the papers to give an idea of the kinds of works that have been done to the moment. The main goal of presenting the summaries is to provide the readers with an idea of the types of works that have been done in the past years on the intersection of the areas of computational intelligence and green computing. These summaries we believe encourage the readers to look for more detail on these papers, as well as in the other related ones in these areas.

In the work by Prakash et al. ${ }^{[15]}$, a hybrid combination of genetic algorithm and artificial neural network (GANN) is applied to the optimization of the energy in a wireless network toward achieving green computing. They focused mainly on the minimization of energy consumption, which was considered as the objective function in a genetic algorithm. An energy savings of 51\% was reported, which demonstrated the advantages of the proposed hybrid G-ANN approach.

In the paper by Carvin et al. ${ }^{[16]}$, an efficient scheduling algorithm using a 3D neural network predictor for green cloud computing is presented. Cloud computing can be viewed as a new technology that plays a key role in the digital world. In this case, scheduling and load balancing are the main problems in this area. The proposed approach presented in this work offers a new 3D neural predictor model for estimating the workload. The approach emphasizes green cloud computing by reducing the power usage and heat.

In the work by Kashyap et al. ${ }^{[17]}$, a new approach for green computing in sensor-enabled Internet of Things with a hybrid intelligent approach for load balancing is presented. The hybrid intelligent approach consists of an adaptive neuro fuzzy clustering algorithm for load balancing for a group of sensors. The adaptive neuro fuzzy clustering algorithm approach outperformed the existing best methods in the literature. 


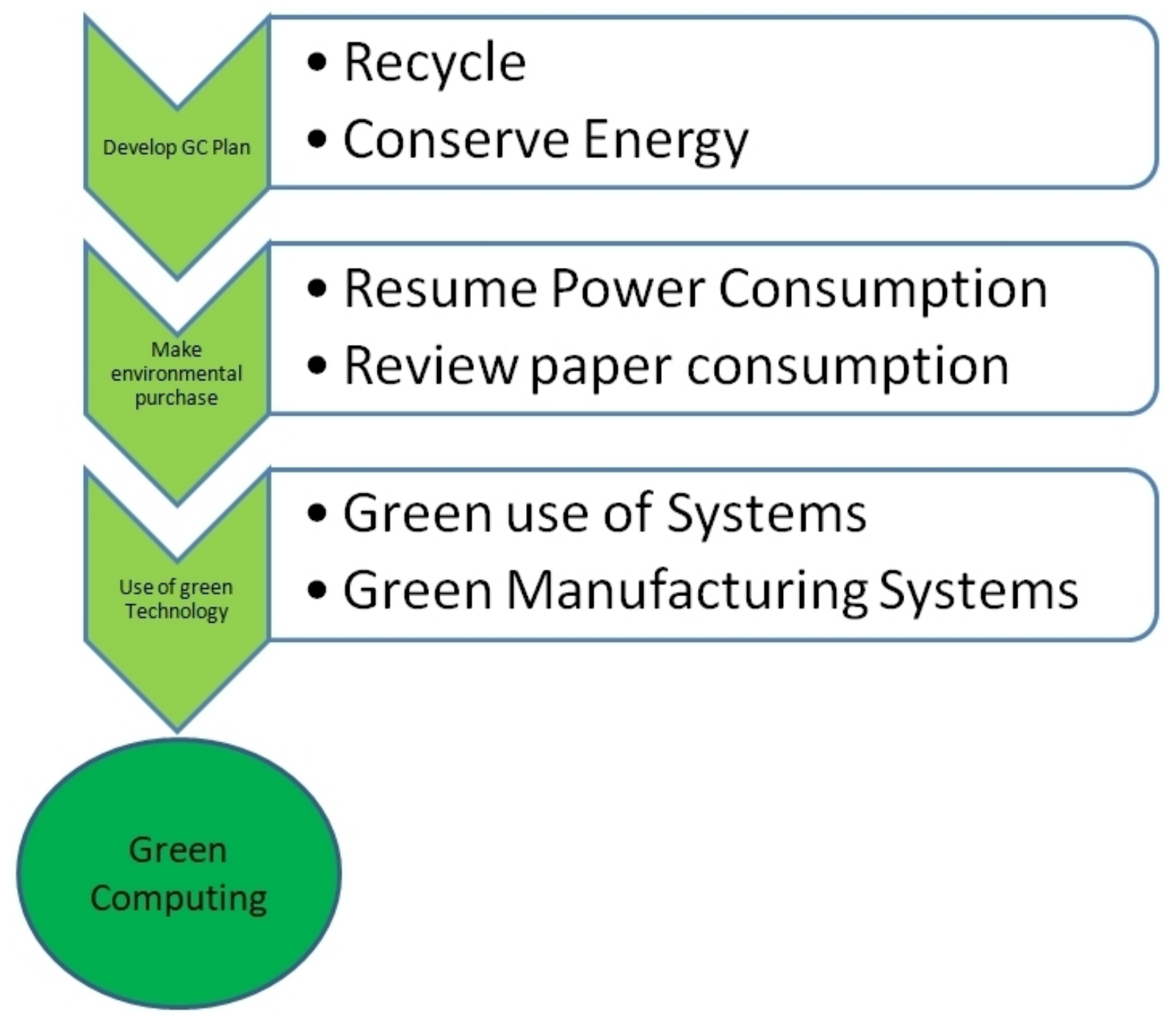

Figure 1. Illustration of the main concepts and components of green computing.

In the paper by Ragmani et al. ${ }^{[18]}$, a new green service for cloud computing based on fuzzy theoretical concepts is proposed. Cloud computing exhibits some key features such as elasticity and economy of scale that enable it to encounter many applications in the scientific, economic and industrial areas. In this work, fuzzy systems based on fuzzy theory are developed to design a cloud architecture that enables service level agreement negotiation with the help of an intelligent module.

In the work of Singh et al. ${ }^{[19]}$, a green computing allocation method using a genetic algorithm and a support vector model is presented. For the allocation, a modified best fit decreasing algorithm is used to check the availability of resources. The genetic approach is used to optimize the modified best fit, decreasing performance based on a pre-defined fitness function.

In the paper by Kaur et al. ${ }^{[20]}$, a good method for green cloud computing based on a genetic algorithm approach is proposed. In this research work, a hybrid efficient energy algorithm based on genetic algorithms is presented. Simulation results clearly show that the proposed algorithm obtains lower energy consumption and reduces violations with high throughput compared to the best existing known algorithm. 
In the work by Theja et al. ${ }^{[21]}$, a genetic algorithm based quality of service oriented green computing approach for virtual machine consolidation in cloud infrastructures is presented. In this work, an evolutive paradigm called adaptive genetic algorithm (A-GA) is proposed for an optimal placement policy in a virtual machine, to be implemented in virtual machine consolidation. The proposed A-GA scheme is shown to produce significant energy savings.

In the paper by Mousavi et al. ${ }^{[2]}$, a novel fuzzy logic approach for the green supplier selection problem with interval type-2 trapezoidal fuzzy numbers for group decision and reducing information loss is presented. In this research work, a new multiple attributes group decision-making model is proposed based on an interval type-2 trapezoidal fuzzy approach and using the statistical concepts of possibilistic mean and standard deviation.

In the work by Bera et al. ${ }^{[23]}$, a green computing supply chain model is proposed for an industrial problem solution with multi-objective optimization approach. For this goal, the total cost of supply chain and total time including loading and unloading of materials for transportation are minimized with the multiobjective approach. Due to the vagueness of the data used in the model, the parameters are assumed to have a triangular fuzzy number form, which produces good results.

In the paper by Jagadish et al. ${ }^{[24]}$, an approach for surface roughness quality prediction for green abrasive water jet machining is presented. The main goal of this work is to achieve an efficient modeling of green composites machining using an intelligent approach based on fuzzy logic theoretical concepts. A hybrid approach combining a Takagi-Sugeno-Kang fuzzy model with the help of subtractive clustering is proposed for surface roughness prediction.

In the work by Kondratenko et al. ${ }^{[25]}$, a green computing approach for the design and optimization of thermoacoustic waste heat utilization plant with the help of fuzzy logic techniques is presented. The research work is aimed at the synthesis of an optimal fuzzy system for thermoacoustic plant control by providing the best working conditions for improving its efficacy. Fuzzy control systems of both Mamdani and Sugeno types are designed and compared to find the best control solution. The proposed fuzzy controllers are compared with the best PD controllers, showing that the fuzzy control is better.

In the paper by Varghese et al. ${ }^{[26]}$, the design and implementation of a traffic flow control system that can adapt to changing conditions with computational intelligence techniques for green signaling is presented. It is nowadays well-known that traffic on urban roads is increasing day by day. In addition, most cities currently rely on a pre-timed traffic control scheme, which is usually not a good solution. This research work presents an alternative by using intelligent traffic flow prediction and control through the use of green signaling, showing very good results.

In the work by Karthiban et al. ${ }^{[27]}$, a novel green computing resource allocation for cloud computing using a modified deep reinforcement learning algorithm is proposed. A reinforcement learning algorithm is used to achieve adaptive behavior in the allocation process. In this research work, an approach for green computing fair resource allocation through a deep reinforcement learning model is proposed to offer an efficient allocation scheme to the users in the network, which shows very good results.

In the work by Zubar et al. ${ }^{[28]}$, an approach for green computing process optimization using a machine learning algorithm is presented. Handling the information is an important task in the healthcare sector; for this reason, data mining techniques are the correct alternative to solve the complex problems in this sector. 
In this research work, the approach of an effective recognition method is proposed for analyzing heart diseases using a hybrid combination of K-nearest neighbor clustering and spiral optimization for risk classification of cardiovascular diseases. The experimental results are extremely promising, and the method can become a helpful tool for medical doctors specializing in heart diseases.

In the paper by Gholipour et al. ${ }^{[29]}$, an energy-aware dynamic resource management technique utilizing a deep learning algorithm approach for achieving green computing in cloud data centers is presented. In this research work, a new energy-aware resource management technique is proposed. This is done by using the concept of joint virtual machines and the container consolidation approach. In addition, a deep learning algorithm for achieving green computing in cloud data centers, to minimize the waste of resources, migration rate and energy, is proposed with very good results.

In the work by Yang et al. ${ }^{[30]}$, a deep reinforcement learning algorithm based on a green resource allocation mechanism in edge computing is proposed. Although deep reinforcement learning has been applied in many studies related to edge networks, there are currently no applications for green resource allocation, which makes this proposed approach very relevant and important in the area of green computing.

In the paper by Kashyap et al..$^{[31]}$, a deep learning based offloading approach for Internet of Things networks with the goal of green computing is proposed. Green computing has recently become a promising solution for supporting the goal of renewable energy in meeting the paradigm of an energy constraint heterogeneous Internet of Things network. A reinforcement learning architecture-based scheme is proposed for achieving the goals of green computing.

In the work by Xu et al..$^{[32]}$, a deep reinforcement learning approach for dynamic access control with battery prediction for mobile-edge computing in green Internet of Things networks is presented. In this research work, benefiting from an energy harvesting technique, the dynamic mobile-edge computing-access control problem is investigated for achieving the goal of maximizing the long-term average uplink transmission rate while minimizing the consumption of transmission energy for green Internet of Things networks. Simulation results of the approach are good when compared with existing traditional approaches.

In the work by Sahu et al. ${ }^{[33]}$, an approach for cloud server optimization with load balancing and green computing techniques is presented. One of the important and key areas in cloud computing is the frequent optimization of the cloud servers. In this research work, a threshold-based compare and balance method for cloud server optimization is proposed for obtaining load balancing, and the experimental results demonstrate the advantages of the method with respect to existing approaches in the literature.

The 18 papers briefly mentioned above constitute a representative sample of the research work that has been done in the areas of computational intelligence and green computing over the past 20 years. We can notice from these papers that there have been applications of fuzzy systems, neural network models, genetic algorithms and swarm intelligence to different types of problems in green computing. In addition, from the above discussion of these papers, we can infer that computational intelligence techniques will continue to have a great impact on the applications of green computing in the future. This great impact could be measured as the goals of green computing that will be achieved to a greater extent and more efficiently in time, as well as in the quantification of the energy savings. We believe that metrics to evaluate this impact will also be proposed in the near future. 


\section{SCIENTOMETRIC ANALYSIS OF GREEN COMPUTING AND COMPUTATIONAL INTELLIGENCE TECHNIQUES}

In this section, the scientometric analysis for the existing published papers in the green computing and computational intelligence areas performed for this work is presented. We present a sequence of plots and tables that show the analysis of the data (published papers) from different points of view or facets used in the analysis. We can say that this analysis helps us understand the nature of the research that has been done in the areas of green computing and computational intelligence. First, we start with a co-authorship analysis of the data. Co-authorship is essential for any scientometric study, and, in the case of the interaction of green computing and computational intelligence techniques, the co-authorship can be visualized in Figure 2. In this case, the figure illustrates the 255 journal papers grouped with respect to co-authorship in more than three papers. Figure 2 provides a view of the collaborative work that has been done in green computing and computational intelligence.

Figure 3 shows a cluster visualization for the main authors based on the 255 papers that have been published from 2001 to 2021. This figure shows authors who are close together working in research collaborations associated to green computing and computational intelligence. The names with larger fonts represent authors with more published papers.

Figure 4 shows the distribution of the 255 papers according to the areas of application. This figure shows that the computer science area has the highest percentage (32.1\%), followed by the engineering area with $21.5 \%$, mathematics with $12.9 \%$ and others with lower percentage values.

Table 1 shows the number of documents for each corresponding area of application. These numbers illustrate the classifications of the papers, chapters in books, conference proceedings and others that are related to green computing and computational intelligence.

Figure 5 shows the total number of documents for each of the top 10 countries that are doing research work in green computing and computational intelligence. This figure shows that India is the top country in number of publications, followed by China, the United States, Canada and other countries.

In Figure 6, we illustrate the general trend on the number of publications per year since 2001, which shows an increasing trend that we believe will continue in the next years. The recent importance of environmental issues and computational intelligence applications for daily activities and industry clearly justifies the increasing trend that is shown in Figure 6 and that we believe will continue in future years.

In Figure 7, we illustrate the plots of the top journals that are publishing more papers on these new areas of green computing and computational intelligence. We can appreciate that the Journal of Green Computing is the one with more published documents. After that, the Journal of Supercomputing is in second place and the Journal of Advanced Research in Dynamical and Control Systems is in third place.

Figure 8 shows the top 10 agencies in the world that are providing funding for doing research on green computing. China, the United States, India and Canada are the countries providing more funding for these areas of research.

Figure 9 summarizes the productivity of the top 10 authors at the intersection of computational intelligence and green computing. In this case, the top author is Kaiwartya with four publications, followed by Kharel 
Table 1. Number of documents for each area

Computer science

Engineering

Mathematics

Environmental science

Social sciences

Business, management and accounting

Physics and astronomy

Energy

Materials science

Decision sciences

Earth and planetary sciences

Pharmacology, toxicology and pharmaceutics

Biochemistry, genetics and molecular biology

Chemical engineering

Multidisciplinary

Arts and humanities

Chemistry

Agricultural and biological sciences

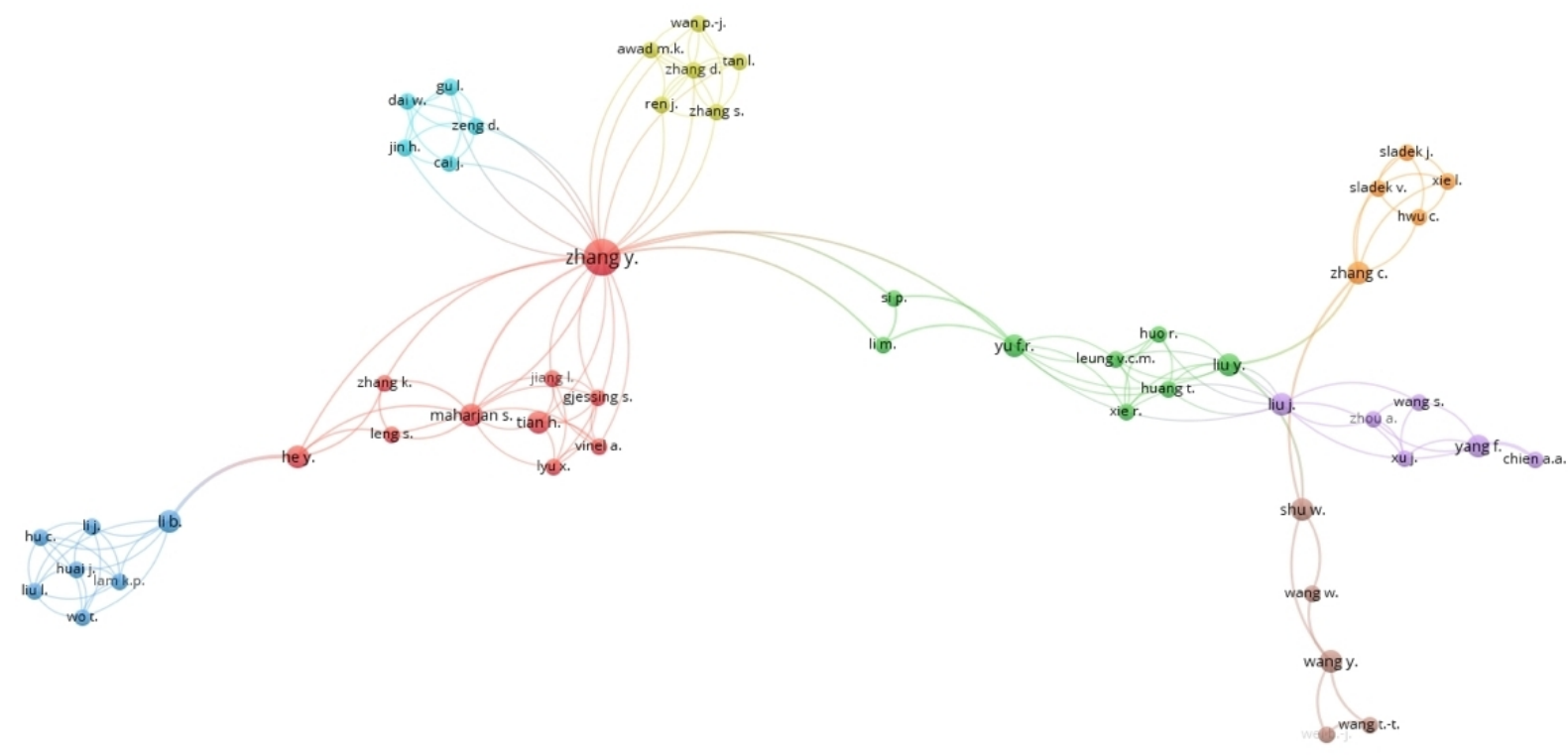

Figure 2. Co-authorship pattern for green computing and computational intelligence.

and then Kumar. After the three top authors, we can find other researchers with fewer publications.

Figure 10 summarizes the productivity of the top 10 institutions at the intersection of computational intelligence and green computing. In this case, the top institution is Vellore Institute of Technology (India) with seven publications, followed by Bharathiar University, Chinese Academy of Sciences and University Teknologi Malaysia with five publications each. 


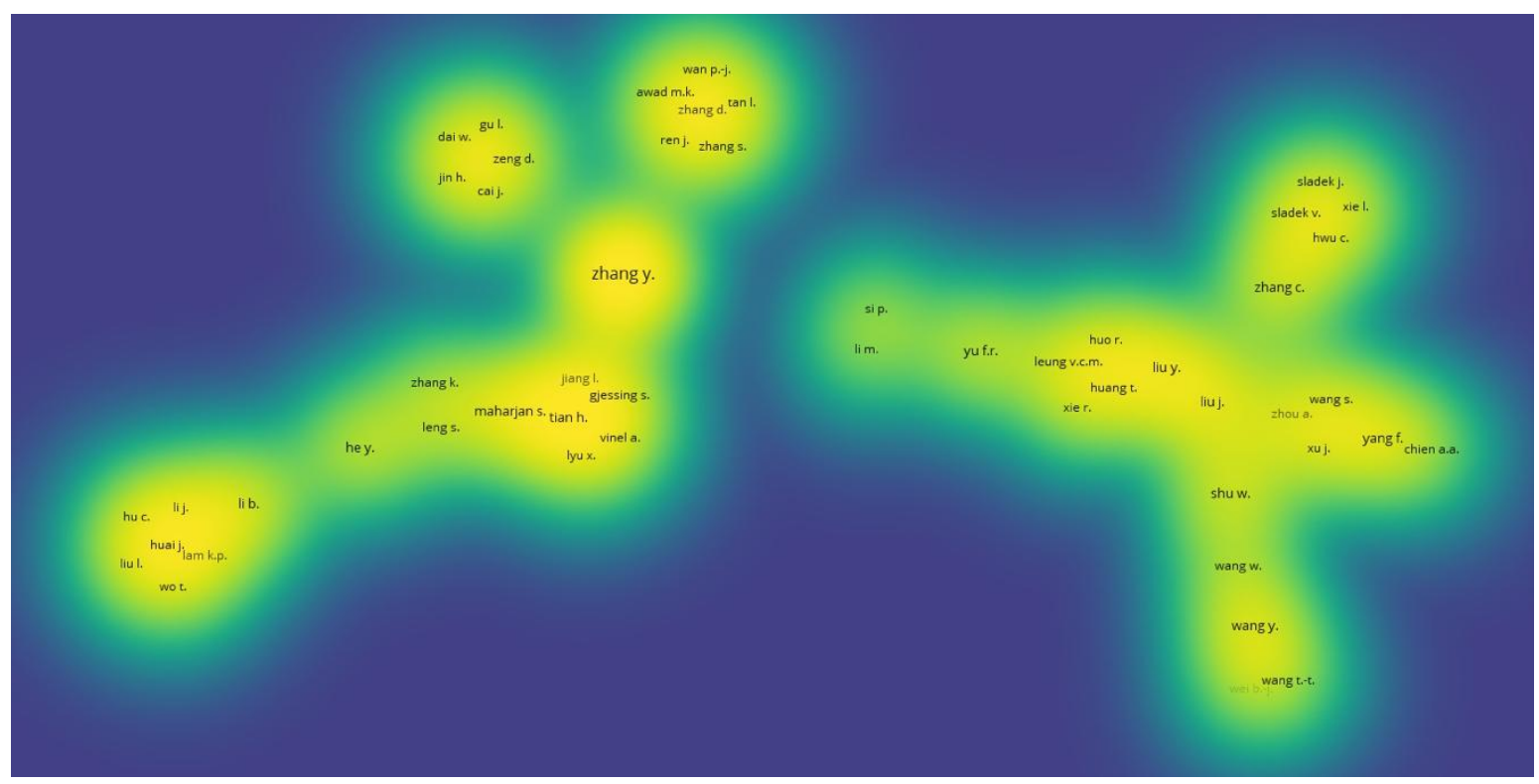

Figure 3. Cluster density visualization of the main authors in green computing and computational intelligence.

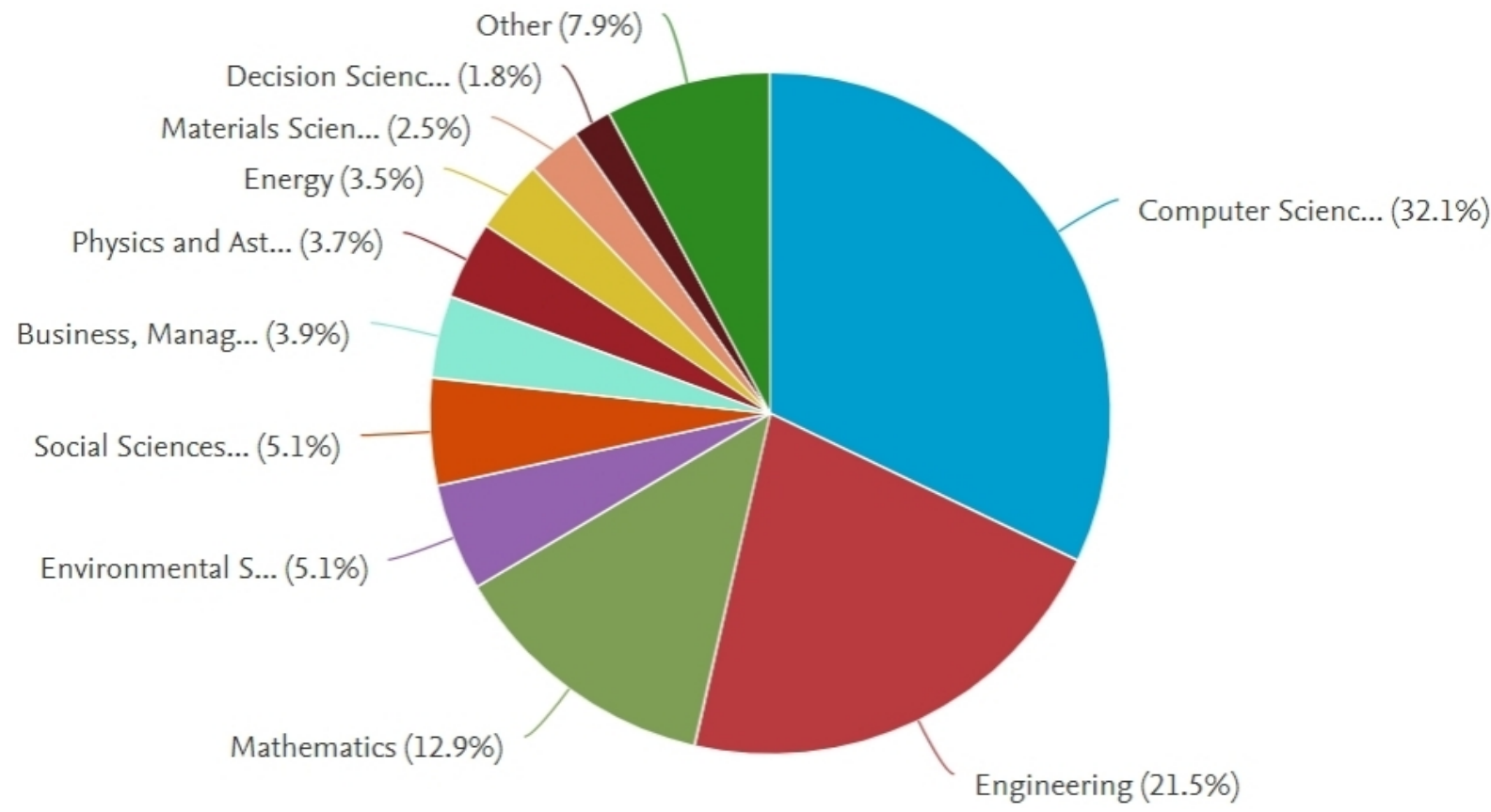

Figure 4. Distribution of papers according to the area of application.

Figure 11 plots the number of citations per year from 2010 to 2021. In this figure, we can appreciate a clear increasing trend, which indicates that the papers are having a greater impact and relevance in the area of green computing. In this figure, we only consider citations for journal papers. In 2020, the number of citations reached the highest value of 800.

Now, Figure 12 shows the top 10 most cited papers in the areas of green computing and computational intelligence. We can notice that the most cited paper (published in 2011) now has 555 citations. Then, there 


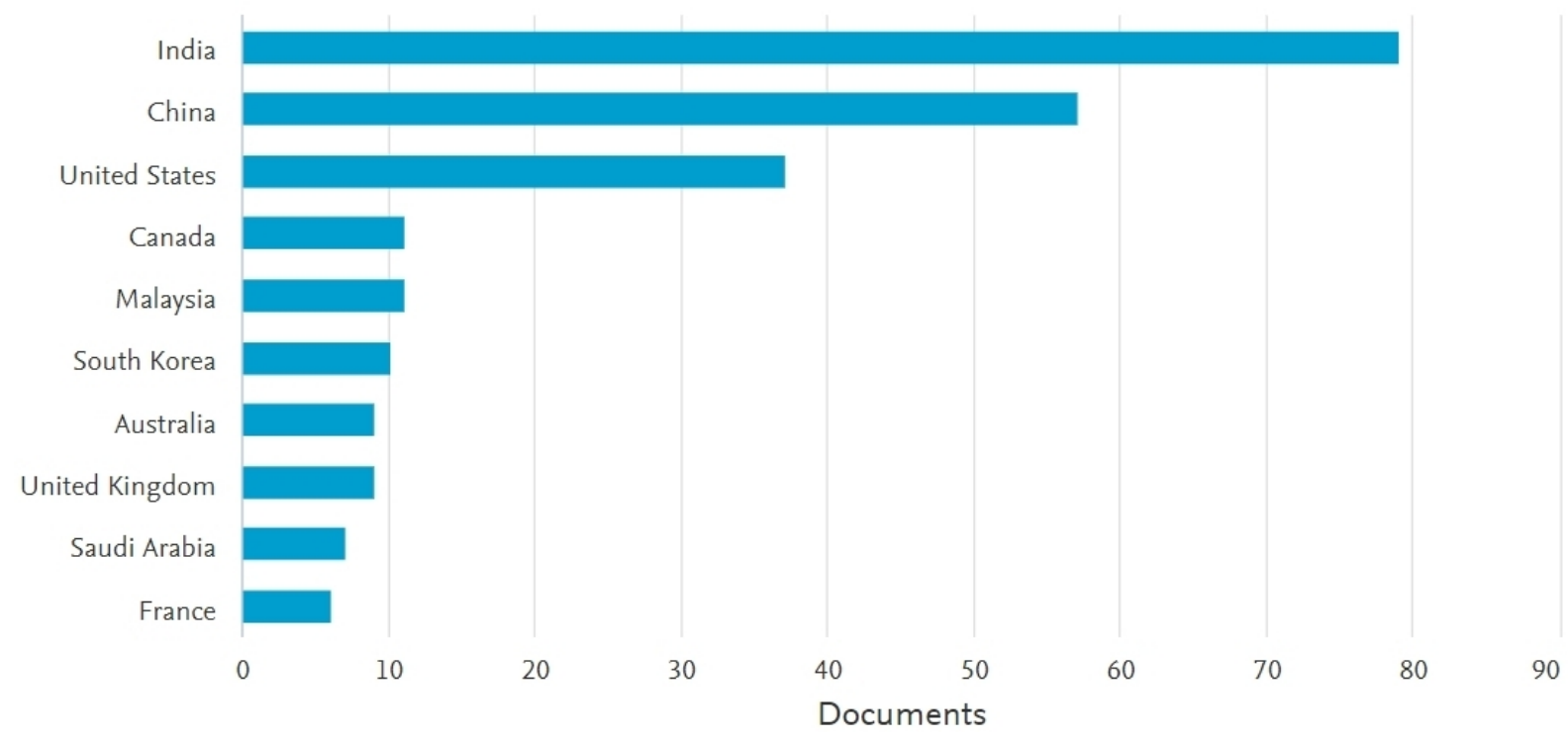

Figure 5. Graphical representation of the total number of documents for each country.

50

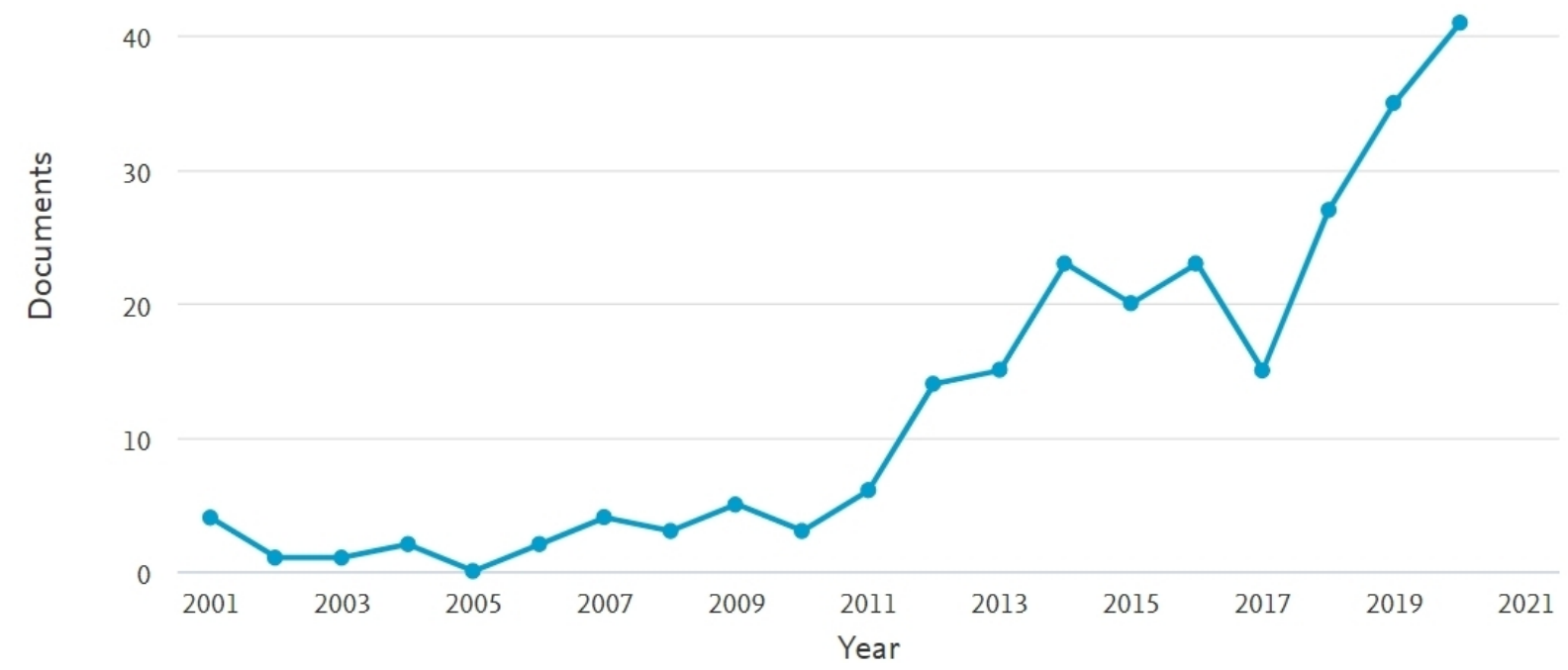

Figure 6. Documents published per year since 2001 on green computing and computational intelligence.

is a paper from 2016 with 351 citations. These citation counts reflect the impact that has been gained by the research that has been done thus far.

We also show the information illustrated in Figure 12 in the form of a table [Table 2] to provide more complete details on the top 10 most cited papers. In Table 2, we can find the complete details of the top 10 papers according to their citations. 
Table 2. List of the top 10 most cited papers on green computing and computational intelligence

\begin{tabular}{|c|c|c|}
\hline $\begin{array}{l}10 \text { most } \\
\text { cited Scopus }\end{array}$ & Paper & $\begin{array}{l}\text { No of citations to } \\
1 / 7 / 2021\end{array}$ \\
\hline 1 & $\begin{array}{l}\text { Baliga J, Ayre RWA, Hinton K, Tucker RS. Green cloud computing: balancing energy in processing, storage, } \\
\text { and transport. Proceedings of the IEEE 2011;99:149-67. }\end{array}$ & 555 \\
\hline 2 & $\begin{array}{l}\text { Gai K, Qiu M, Zhao H, Tao L, Zong Z. Dynamic energy-aware cloudlet-based mobile cloud computing } \\
\text { model for green computing. Journal of Network and Computer Applications 2016;59:46-54. }\end{array}$ & 351 \\
\hline 3 & $\begin{array}{l}\text { Farahnakian F, Ashraf A, Pahikkala T, et al. Using ant colony system to consolidate VMs for green cloud } \\
\text { computing. IEEE Transactions on Services Computing 2015;8:187-98. }\end{array}$ & 177 \\
\hline 4 & $\begin{array}{l}\text { Hisada Y. An efficient method for computing Green's functions for a layered half-space with sources and } \\
\text { receivers at close depths. Bulletin - Seismological Society of America 1994;84:1456-72. }\end{array}$ & 170 \\
\hline 5 & $\begin{array}{l}\text { Sarkar S, Misra S. Theoretical modelling of fog computing: a green computing paradigm to support loT } \\
\text { applications. IET Networks 2016;5:23-9. }\end{array}$ & 153 \\
\hline 6 & Kurp P. Green computing. Communications of the ACM 2008;51:11-3. & 151 \\
\hline 7 & $\begin{array}{l}\text { Murtazaev A, Oh S. Sercon: server consolidation algorithm using live migration of virtual machines for } \\
\text { green computing. IETE Technical Review Institution of Electronics and Telecommunication Engineers, India } \\
\text { 2011;28:212-31. }\end{array}$ & 119 \\
\hline 8 & $\begin{array}{l}\text { Li J, Li B, Wo T, et al. CyberGuarder: a virtualization security assurance architecture for green cloud } \\
\text { computing. Future Generation Computer Systems 2012;28:379-90. }\end{array}$ & 105 \\
\hline 9 & $\begin{array}{l}\text { Hisada Y. An efficient method for computing Green's functions for a layered half-space with sources and } \\
\text { receivers at close depths (Part 2). Bulletin - Seismological Society of America 1995;85:1080-93. }\end{array}$ & 98 \\
\hline 10 & $\begin{array}{l}\text { Zhang K, Leng S, He Y, Maharjan S, Zhang Y. Mobile edge computing and networking for green and low- } \\
\text { latency internet of things. IEEE Communications Magazine 2018;56:39-45. }\end{array}$ & 88 \\
\hline
\end{tabular}

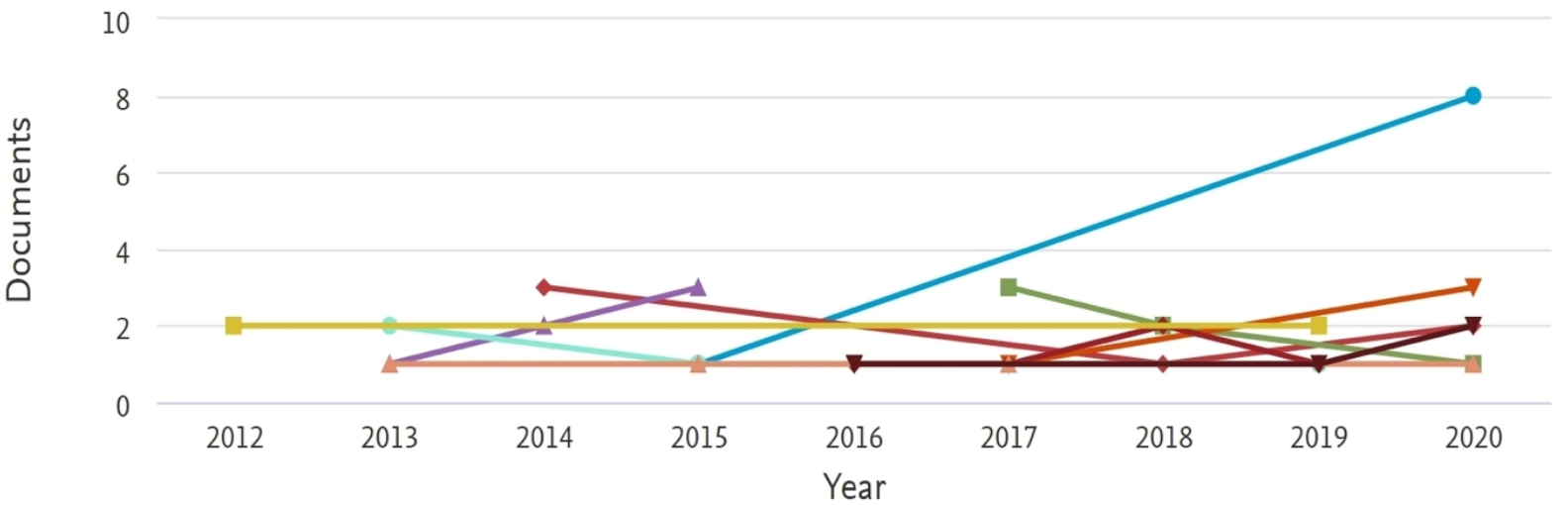

\footnotetext{
- Journal Of Green Engineering $\leadsto$ Journal Of Supercomputing

- Journal Of Advanced Research In Dynamical And Control Systems

$\leftarrow$ International Journal Of Applied Engineering Research $\quad$ - IEEE Access $\sim$ Cluster Computing

$\rightarrow$ IEEE Communications Magazine - Future Generation Computer Systems

$\neq$ IEEE Transactions On Cloud Computing $\neq$ Simulation Modelling Practice And Theory
}

Figure 7. Top 10 journals publishing papers on green computing and computational intelligence.

Finally, we show a distribution by area of the top 10 most cited papers in Figure 13. This figure shows that most of the papers have been published in the computer science area, followed by the engineering and decision science areas.

The figures and tables presented above provide a general overview of what has been done thus far in research in these areas of green computing and computational intelligence and are the basis for envisioning possible future works, which is the main topic of Section 4. In particular, we also consider the sub-areas of both green computing and computational intelligence to analyze their trends and impact on real world 


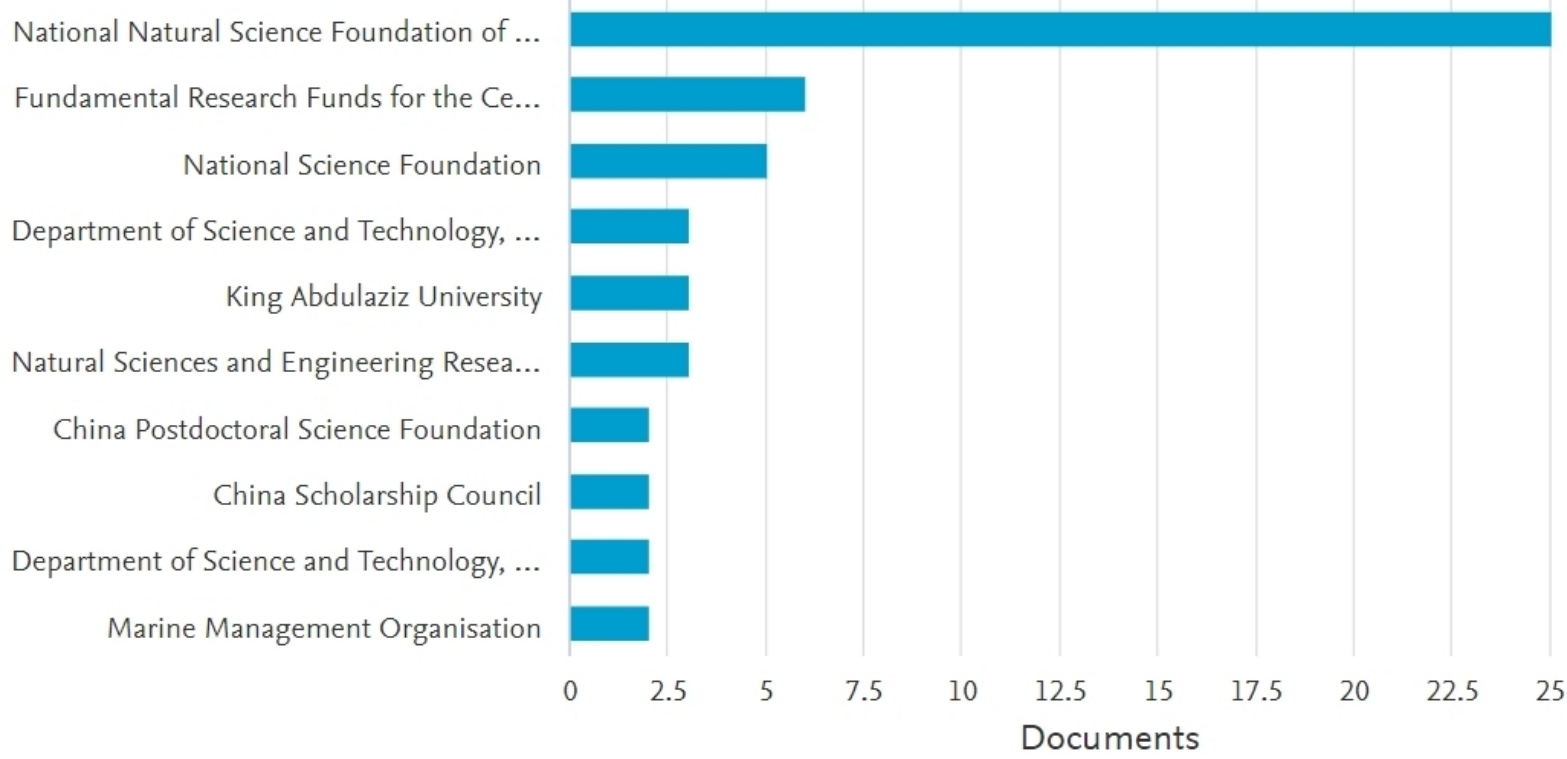

Figure 8. Top agencies in the world providing funding for research on green computing.

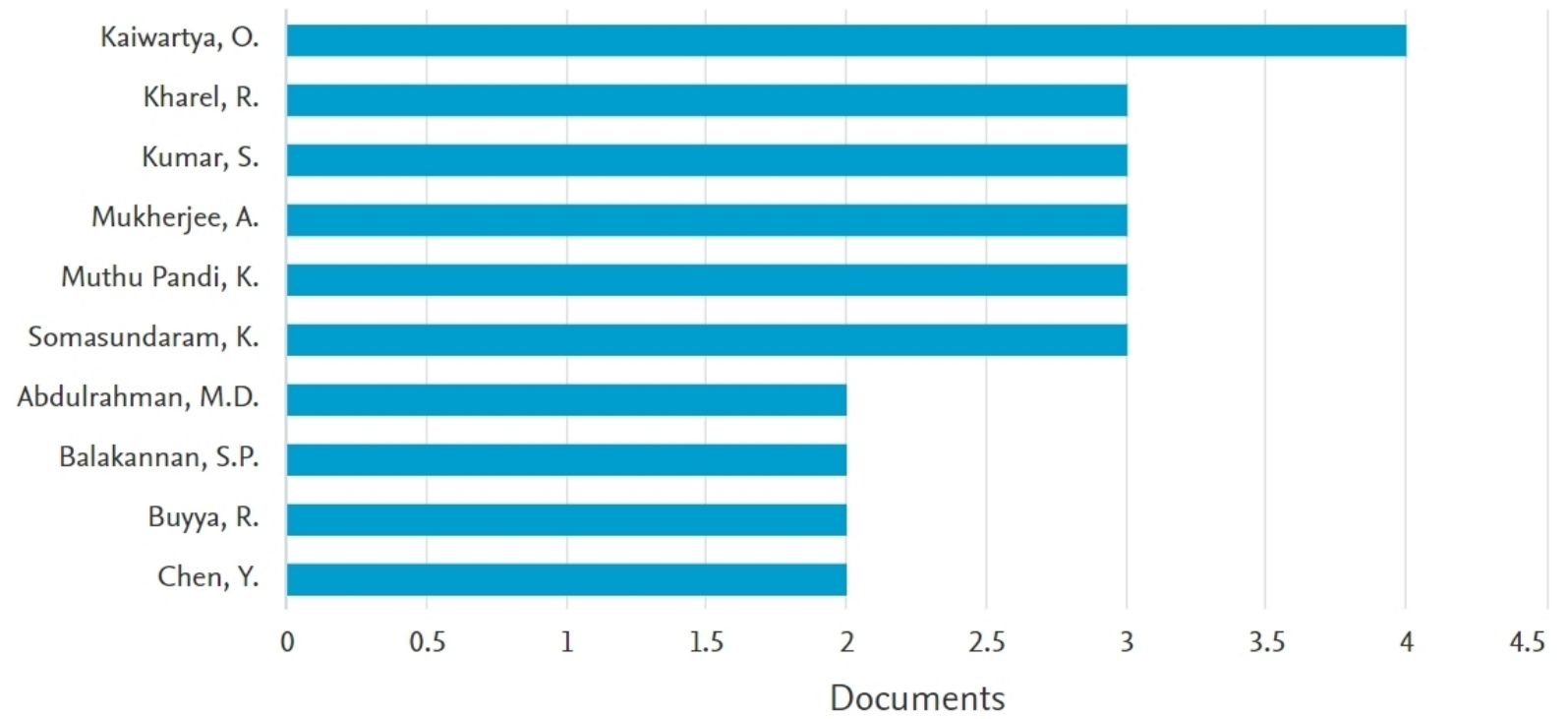

Figure 9. Top 10 authors in the world on the computational intelligence and green computing areas.

applications.

\section{POSSIBLE FUTURE TRENDS OF RESEARCH}

Based on the papers described in the previous sections and the performed scientometric analysis, we can say that computational models such as fuzzy logic, neural networks, genetic algorithms and swarm intelligence techniques have been used in green computing applications. We believe that more papers will come in future years with these same intelligent techniques, as there are many key problems in green computing that can be tackled with these techniques that have not been considered yet. However, there are still other kinds of models coming from the computational intelligence area that can be applied to green computing 


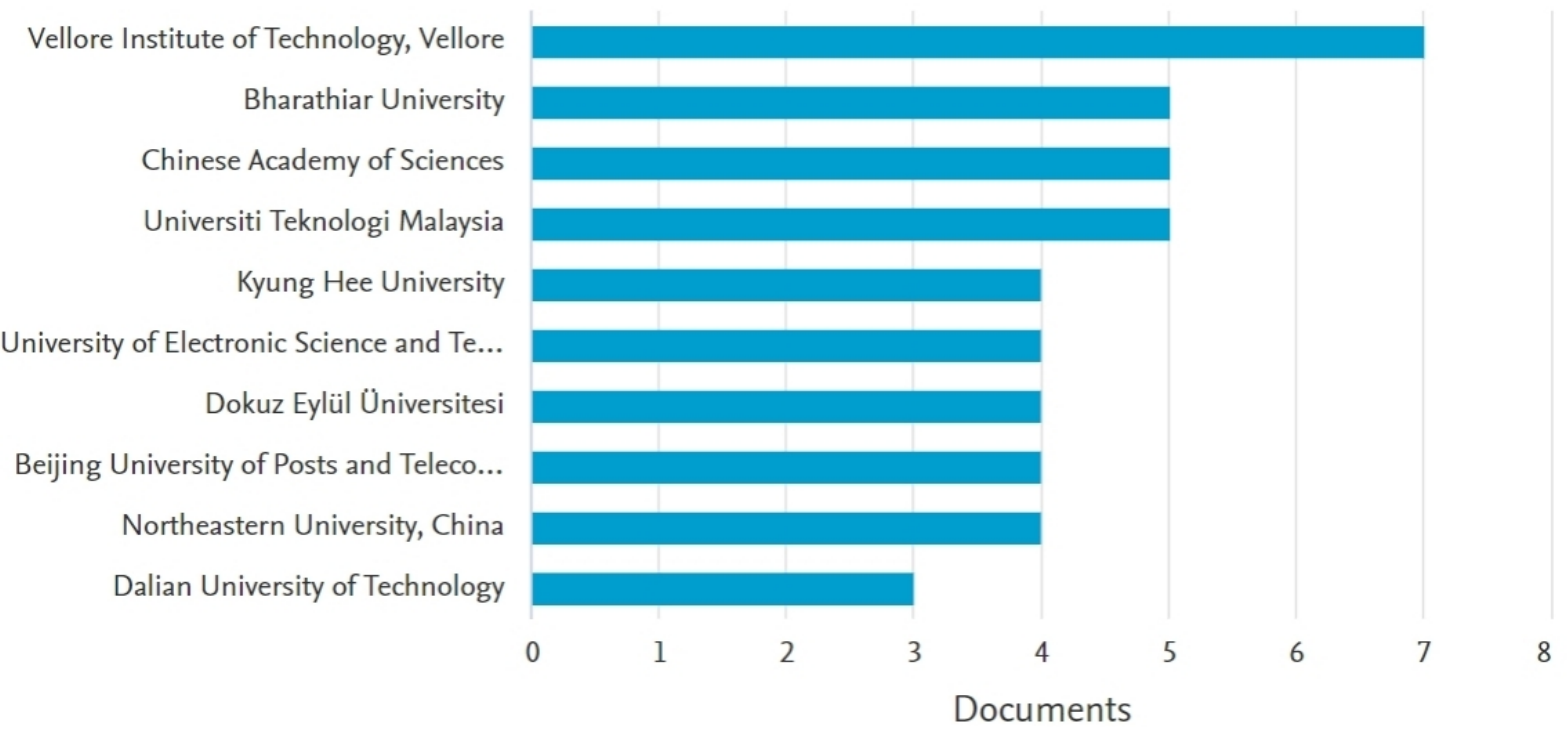

Figure 10. Top 10 institutions in the world for computational intelligence and green computing.

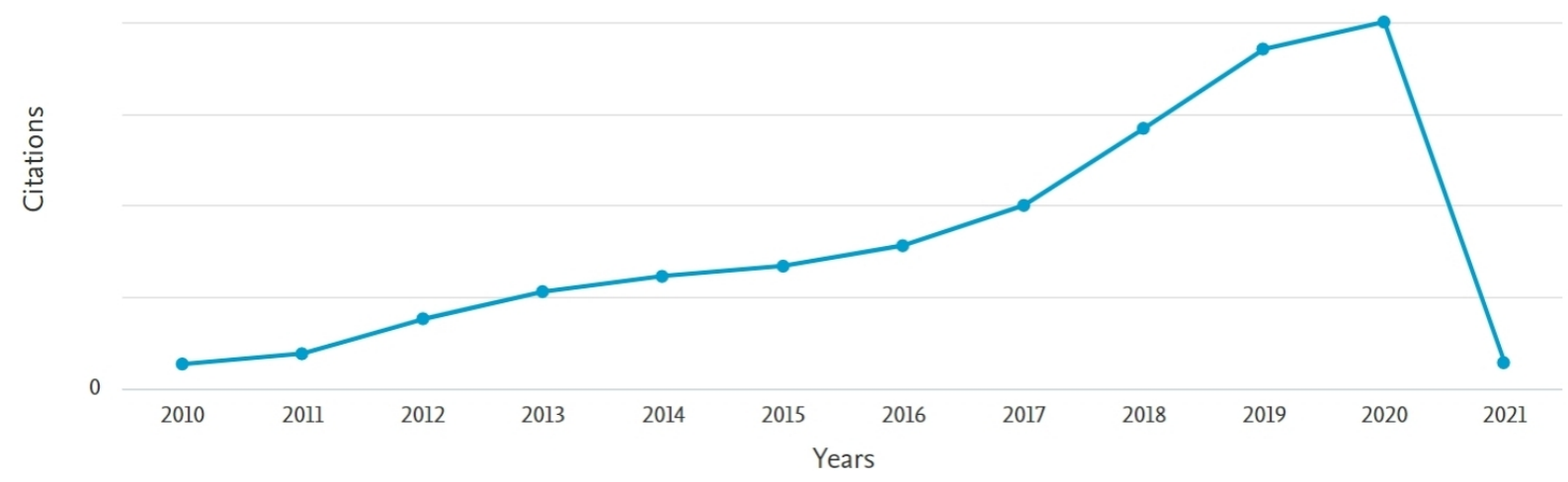

Figure 11. Citations of papers per year since 2010 on green computing and computational intelligence.

problems. For example, some swarm intelligent and nature-inspired methods, such as particle swarm optimization, ant colony optimization, grey wolf optimization, firefly algorithm and other similar methods $s^{[34-39]}$, have not been yet applied in green computing problems. In addition, other extensions of the original fuzzy logic (that is now called type-1) are still to be considered; for example, general type-2 fuzzy systems, intuitionistic fuzzy logic, fractional fuzzy systems, hesitant fuzzy systems and others ${ }^{[40-44]}$ have not been applied yet in green computing. Finally, new neural models, such as modular neural networks and convolutional neural models, as well as type-2 fuzzy neural hybrid systems, are also to be considered in green computing problems $\mathrm{s}^{[45-50]}$. Finally, there are many opportunities for future research work on applying computational intelligence techniques in the green computing area, and we envision this will continue to be a fruitful area of research in the short, medium and long terms.

Finally, the computational intelligence area is also evolving in new directions, such as the use of quantum computing, nanotechnology and other newer technologies that may come to be developed in conjunction with intelligent techniques and models. Thus, we expect that, as the computational intelligence area evolves 


\begin{tabular}{|c|c|c|c|c|c|c|c|c|c|c|c|c|c|c|c|c|c|}
\hline Documents & Citations & $<2010$ & 2010 & 2011 & 2012 & 2013 & 2014 & 2015 & 2016 & 2017 & 2018 & 2019 & 2020 & 2021 & Subtotal & $>2021$ & Total \\
\hline & Total & 331 & 54 & $\pi$ & 152 & 212 & 246 & 268 & 313 & 400 & 568 & 741 & 800 & 57 & 3888 & 0 & 4219 \\
\hline Green cloud computing: Balancing energy in processing, stora... & 2011 & & & 23 & 65 & 83 & 93 & 68 & 68 & 49 & 44 & 40 & 20 & 2 & 555 & & 555 \\
\hline Dynamic energy-aware cloudlet-based mobile cloud computing m... & 2016 & & & & & & & & 34 & 64 & 116 & 85 & 51 & 1 & 351 & & 351 \\
\hline Using Ant Colony System to Consolidate VMs for Green Cloud C... & 2015 & & & & & & & 5 & 9 & 30 & 36 & 50 & 43 & 4 & 177 & & 177 \\
\hline An efficient method for computing Green's functions for a la... & 1994 & 64 & 9 & 6 & 8 & 16 & 8 & 11 & 11 & 12 & 7 & 11 & 7 & & 106 & & 170 \\
\hline Theoretical modelling of fog computing: A green computing pa... & 2016 & & & & & & & & 4 & 20 & 44 & 44 & 38 & 3 & 153 & & 153 \\
\hline Green Computing & 2008 & 7 & 11 & 12 & 15 & 16 & 16 & 21 & 17 & 4 & 7 & 16 & 6 & 3 & 144 & & 151 \\
\hline Sercon: Server consolidation algorithm using live migration ... & 2011 & & & & 4 & 11 & 10 & 17 & 14 & 14 & 17 & 14 & 18 & & 119 & & 119 \\
\hline CyberGuarder: A virtualization security assurance architectu... & 2012 & & & 2 & 8 & 15 & 15 & 17 & 9 & 9 & 12 & 7 & 11 & & 105 & & 105 \\
\hline An efficient method for computing Green's functions for a la... & 1995 & 36 & 4 & 4 & 6 & 8 & 5 & 5 & 3 & 10 & 6 & 5 & 6 & & 62 & & 98 \\
\hline Mobile Edge Computing and Networking for Green and Low-Laten... & 2018 & & & & & & & & & & 4 & 37 & 43 & 4 & 88 & & 88 \\
\hline
\end{tabular}

Figure 12. Citations of papers per year since 2010 on green computing and computational intelligence.

\section{Documents by subject area}

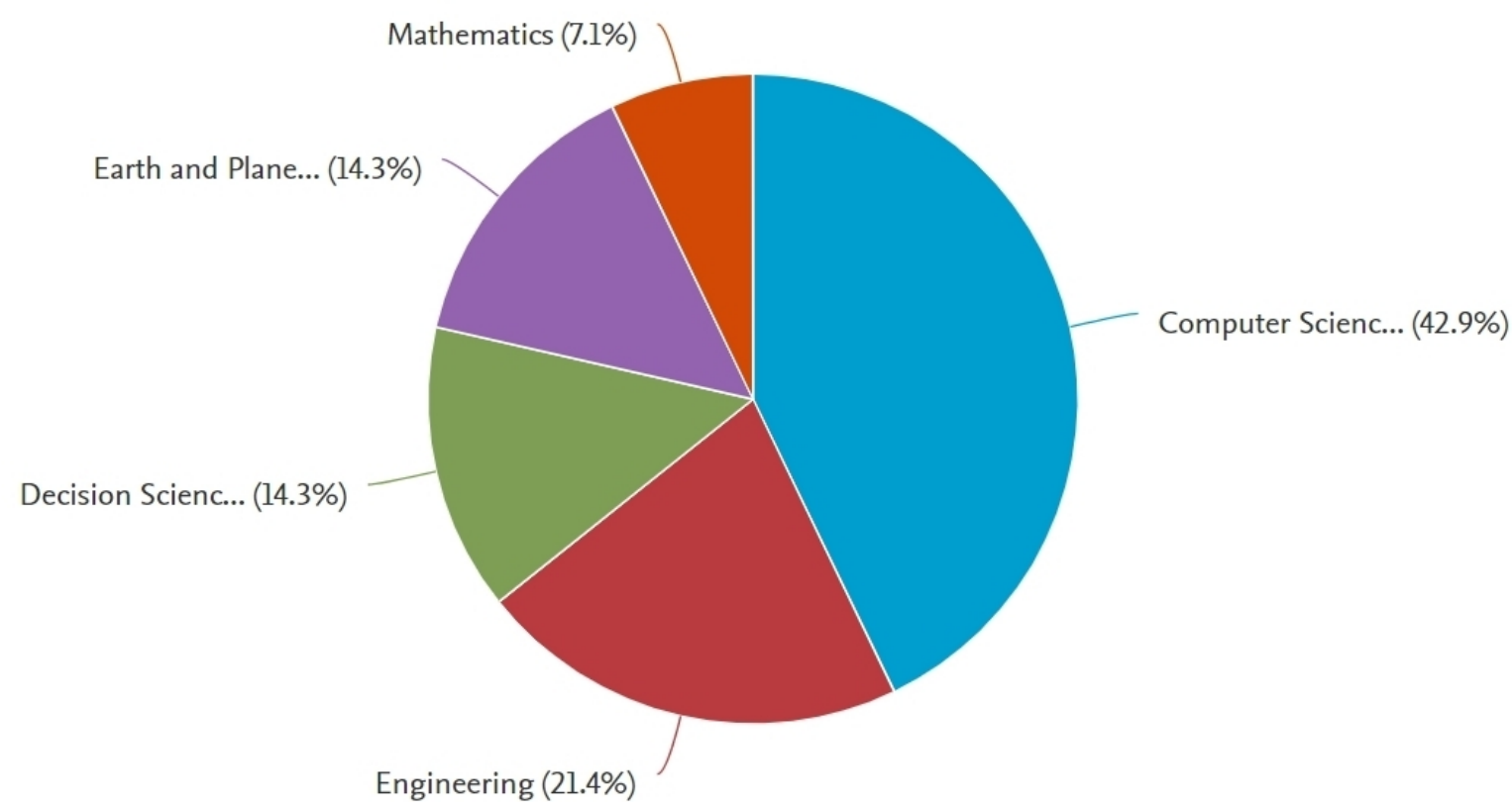

Figure 13. Distribution of the top cited papers per application area.

with new theory and concepts, newer methods will be used for solving in a better way the existing problems in green computing. It is also possible that new problems will arise in green computing that may motivate the development of new theories and concepts in the computational intelligence area.

\section{CONCLUSIONS}

A relatively large volume of literature on green computing with computational intelligence techniques during the period of 2001-2020 recorded in Scopus of Elsevier was studied and analyzed with 
scientometrics. Various scientometric tools were employed in this research study to understand the patterns of growth in this field. Based on the results and findings, the following observations were made.

In total, 255 papers were found for a period of 20 years. Until 2009, the growth had a slow pace. After 2010, this research area has shown an escalating growth in the number of research publications (except for 2017). Significant growth in the literature was noticed in the last 10 years. More than $80 \%$ of the growth was observed after 2010 [Figure 6]. We describe in more detail a representative sample of these papers, which illustrates the types of studies that have been made in this area.

The maximum number of articles was published by researchers in India, followed by those China, the United States, Canada, Malaysia and South Korea. The growth rate was linear until 2009, after which there was a slight decline in 2010. Since 2010, there has been a consistent growth of the output of published articles. The significance of this paper is the presentation in a unified way of the main concepts of green computing and computational intelligence, as well their current and future applications. We strongly believe that this paper can help lay the foundation for a new hybrid area combining green computing with computational intelligence, which would be very important because up to now both areas have been flourishing apart and they could both benefit greatly by interacting with each other.

This study provides valuable information for academicians, research scholars and people interested in scientometric analytical views of green computing and computational intelligence techniques. As future work, we imagine the researchers putting forward the application of generalized type-2 fuzzy logic, modular neural networks, evolutionary and swarm intelligence techniques or hybrid combinations of these methods, in green computing for solving real-world problems in many areas of application. We also plan to make a study of the sub-areas of both green computing and computational intelligence to analyze their trends and impact on real world applications.

\section{DECLARATIONS}

\section{Authors' contributions}

Made substantial contributions to conception and design of the study and performed data analysis and interpretation: Castillo O

Performed data acquisition, software simulations, as well as provided administrative, technical, and material support: Melin P

\section{Availability of data and materials}

Not applicable.

\section{Financial support and sponsorship}

None.

\section{Conflicts of interest}

Both authors declared that there are no conflicts of interest.

\section{Ethical approval and consent to participate}

Not applicable.

\section{Consent for publication}

Not applicable. 


\section{Copyright}

(C) The Author(s) 2021.

\section{REFERENCES}

1. Aspon SZ, Mohamed Murid AH, M. S. Nasser M, Rahmat H. Integral equation approach for computing green's function on doubly connected regions via the generalized neumann kernel. Jurnal Teknologi 2014:71. DOI

2. Baliga J, Ayre RWA, Hinton K, Tucker RS. Green cloud computing: balancing energy in processing, storage, and transport. Proc IEEE 2011;99:149-67. DOI

3. Benotmane Z, Belalem G, Neki A. Towards a cloud computing in the service of green logistics. IJLSM 2018;29:37. DOI

4. Ahmad TB, Nordin MS. University students' subjective knowledge of green computing and pro-environmental behavior. IES 2014;7:64-74. DOI

5. Ibrahim A. Understanding the factors affecting the adoption of green computing in the gulf universities. ijacsa 2018;9:304-11. DOI

6. Alarifi A, Dubey K, Amoon M, et al. Energy-efficient hybrid framework for green cloud computing. IEEE Access 2020;8:115356-69. DOI

7. Castillo O, Melin P. A new fuzzy-fractal-genetic method for automated mathematical modelling and simulation of robotic dynamic systems. 1998 IEEE International Conference on Fuzzy Systems Proceedings; IEEE World Congress on Computational Intelligence (Cat. No.98CH36228); 1998, p. 1182-7.

8. Castillo O, Melin P. Intelligent adaptive model-based control of robotic dynamic systems with a hybrid fuzzy-neural approach. Applied Soft Computing 2003;3:363-78. DOI

9. Melin P, Sánchez D. Multi-objective optimization for modular granular neural networks applied to pattern recognition. Information Sciences 2018;460-461:594-610. DOI

10. Olivas F, Valdez F, Castillo O, Melin P. Dynamic parameter adaptation in particle swarm optimization using interval type-2 fuzzy logic. Soft Comput 2016;20:1057-70. DOI

11. Castillo O, Castro JR, Melin P, Rodriguez-diaz A. Application of interval type-2 fuzzy neural networks in non-linear identification and time series prediction. Soft Comput 2014;18:1213-24. DOI

12. Ontiveros E, Melin P, Castillo O. High order $\alpha$-planes integration: A new approach to computational cost reduction of General Type-2 Fuzzy Systems. Eng Appl Artif Intell 2018;74:186-97. DOI

13. Berciu M. On computing the square lattice Green's function without any integrations. J Phys A: Math Theor 2009;42:395207. DOI

14. Dharan GB, Jayalakshmi S. Harnessing green cloud computing- an energy efficient methodology for business agility and environmental sustainability. IJETER 2020;8:4193-200. DOI

15. Prakash B, Jayashri S, Karthik TS. A hybrid genetic artificial neural network (G-ANN) algorithm for optimization of energy component in a wireless mesh network toward green computing. Soft Comput 2019;23:2789-98. DOI

16. Carvin LB, Kumar ADV, Arockiam L. ENNEGCC-3D energy efficient scheduling algorithm using 3-D neural network predictor for Green Cloud Computing environment. 2017 International Conference on Intelligent Computing, Instrumentation and Control Technologies; Kannur(IN); 2017, p. 1316.

17. Kashyap P, Kumar S, Dohare U, Kumar V, Kharel R. Green computing in sensors-enabled internet of things: neuro fuzzy logic-based load balancing. Electronics 2019;8:384. DOI

18. Ragmani A, El Omri A, Abhgour N, Moussaid K, Rida M. A novel green service level agreement for cloud computing using fuzzy logic. CLOSER 2018 - proceedings of the 8th International Conference on Cloud Computing and Services Science; 2018, p. 658.

19. Singh G, Mahajan M. A green computing supportive allocation scheme utilizing genetic algorithm and support vector machine. IJITEE 2019;8:760-6. DOI

20. Kaur B, Kaur A. An efficient approach for green cloud computing using genetic algorithm. Proceedings on 2015 1st International Conference on next generation computing technologies; 2015, p. 10.

21. Theja P, Khadar Babu SK. An adaptive genetic algorithm based robust qos oriented green computing scheme for vm consolidation in large scale cloud infrastructures. Indian Journal of Science and Technology 2015:8. DOI

22. Mousavi SM, Foroozesh N, Zavadskas EK, Antucheviciene J. A new soft computing approach for green supplier selection problem with interval type-2 trapezoidal fuzzy statistical group decision and avoidance of information loss. Soft Comput 2020;24:12313-27. DOI

23. Bera S, Jana DK, Basu K, Maiti M. Novel multi-objective green supply chain model with CO2 emission cost in fuzzy environment via soft computing technique. Studies in Computational Intelligence; 2020, p. 463-80.

24. Bhowmik S, Ray A. Prediction of surface roughness quality of green abrasive water jet machining: a soft computing approach. $J$ Intell Manuf 2019;30:2965-79. DOI

25. Kondratenko Y, Korobko V, Korobko O, Kondratenko G, Kozlov O. Green-IT approach to design and optimization of thermoacoustic waste heat utilization plant based on soft computing. Studies in Systems, Decision and Control; 2017, p. 287-311.

26. Varghese A, Bajaj P, Malik L. Design of adaptive traffic flow control system with soft computing tools for green signaling. 2013 International Conference on Human Computer Interactions; 2013.

27. Karthiban K, Raj JS. An efficient green computing fair resource allocation in cloud computing using modified deep reinforcement learning algorithm. Soft Comput 2020;24:14933-42. DOI

28. Zubar AH, Balamurugan R. Green computing process and its optimization using machine learning algorithm in healthcare sector. Mobile Netw Appl 2020;25:1307-18. DOI 
29. Gholipour N, Shoeibi N, Arianyan E. An energy-aware dynamic resource management technique using deep q-learning algorithm and joint VM and container consolidation approach for green computing in cloud data centers. Advances in Intelligent Systems and Computing; 2021, p. 227-33.

30. Yang M, Yu P, Wang Y, et al. Deep reinforcement learning based green resource allocation mechanism in edge computing driven power internet of things. 2020 International Wireless Communications and Mobile Computing; 2020, p. 388.

31. Kashyap PK, Kumar S, Jaiswal A. Deep learning based offloading scheme for IoT networks towards green computing. Proceedings IEEE International Conference on Industrial Internet Cloud; 2019, p. 22.

32. Xu L, Qin M, Yang Q, Kwak K. Deep reinforcement learning for dynamic access control with battery prediction for mobile-edge computing in green IoT networks. 2019 11th International Conference on Wireless Communications and Signal Processing; 2019.

33. Sahu Y, Pateriya RK, Gupta RK. Cloud server optimization with load balancing and green computing techniques using dynamic compare and balance algorithm. 2013 5th International Conference and Computational Intelligence and Communication Networks; Mathura; 2013, p. 527-31.

34. Castillo O, Amador-Angulo L. A generalized type-2 fuzzy logic approach for dynamic parameter adaptation in bee colony optimization applied to fuzzy controller design. Inf Sci 2018;460-461:476-96. DOI

35. Olivas F, Valdez F, Castillo O, Gonzalez CI, Martinez G, Melin P. Ant colony optimization with dynamic parameter adaptation based on interval type-2 fuzzy logic systems. Applied Soft Computing 2017;53:74-87. DOI

36. Sánchez D, Melin P, Castillo O. Optimization of modular granular neural networks using a firefly algorithm for human recognition. Eng Appl Artif Intell 2017;64:172-86. DOI

37. González B, Valdez F, Melin P, Prado-arechiga G. Fuzzy logic in the gravitational search algorithm for the optimization of modular neural networks in pattern recognition. Expert Systems with Applications 2015;42:5839-47. DOI

38. González B, Valdez F, Melin P, Prado-arechiga G. Fuzzy logic in the gravitational search algorithm enhanced using fuzzy logic with dynamic alpha parameter value adaptation for the optimization of modular neural networks in echocardiogram recognition. Applied Soft Computing 2015;37:245-54. DOI

39. Miramontes I, Guzman J, Melin P, Prado-arechiga G. Optimal design of interval Type-2 fuzzy heart rate level classification systems using the bird swarm algorithm. Algorithms 2018;11:206. DOI

40. Gonzalez CI, Melin P, Castro JR, Castillo O, Mendoza O. Optimization of interval type-2 fuzzy systems for image edge detection. Applied Soft Computing 2016;47:631-43. DOI

41. Tai K, El-sayed A, Biglarbegian M, Gonzalez C, Castillo O, Mahmud S. Review of recent Type-2 fuzzy controller applications. Algorithms 2016;9:39. DOI

42. Melin P, Gonzalez CI, Castro JR, Mendoza O, Castillo O. Edge-detection method for image processing based on generalized Type-2 fuzzy logic. IEEE Trans Fuzzy Syst 2014;22:1515-25. DOI

43. Castillo O, Melin P. A review on interval type-2 fuzzy logic applications in intelligent control. Information Sciences 2014;279:615-31. DOI

44. Gaxiola F, Melin P, Valdez F, Castro JR, Castillo O. Optimization of type-2 fuzzy weights in backpropagation learning for neural networks using GAs and PSO. Applied Soft Computing 2016;38:860-71. DOI

45. Melin P, Castillo O. Intelligent control of complex electrochemical systems with a neuro-fuzzy-genetic approach. IEEE Transactions on Industrial Electronics 2001;48:951-5. DOI

46. Sanchez MA, Castillo O, Castro JR, Melin P. Fuzzy granular gravitational clustering algorithm for multivariate data. Information Sciences 2014;279:498-511. DOI

47. Sánchez D, Melin P. Optimization of modular granular neural networks using hierarchical genetic algorithms for human recognition using the ear biometric measure. Eng Appl Artif Intell 2014;27:41-56. DOI

48. Sanchez MA, Castro JR, Castillo O, Mendoza O, Rodriguez-diaz A, Melin P. Fuzzy higher type information granules from an uncertainty measurement. Granul Comput 2017;2:95-103. DOI

49. Melin P, Miramontes I, Prado-arechiga G. A hybrid model based on modular neural networks and fuzzy systems for classification of blood pressure and hypertension risk diagnosis. Expert Systems with Applications 2018;107:146-64. DOI

50. Guzmán J, Miramontes I, Melin P, Prado-arechiga G. Optimal genetic design of Type-1 and interval Type-2 fuzzy systems for blood pressure level classification. Axioms 2019;8:8. DOI 